\title{
Review
}

\section{Esophageal Cancer and Treatment Modalities}

\author{
Takalkar Unmesh Vidyadhar, MS ${ }^{1 *}$; Umesh Kulkarni, MS $^{2}$ \\ ${ }^{1}$ Chief Medical Director, Department of Gastroenterology, United CIIGMA Hospital, Aurangabad, Maharashtra, India \\ ${ }^{2}$ Consultant, Department of Gastroenterology, United CIIGMA Hospital, Aurangabad, Maharashtra, India
}

${ }^{*}$ Correspondence to: Takalkar Unmesh Vidyadhar, MS; United CIIGMA Hospital, Plot No. 6, 7, Survey No. 10, Shahanoorwadi Dargah Road, Aurangabad-431005, Maharashtra, India; Tel. +91-240-6676666, +91-9822042425; E-mail: drunmesh.aurangabad@gmail.com

Received: August 30 $0^{\text {th }}, 2018$; Accepted: August 30 $0^{\text {th }}, 2018$; Published: September $5^{\text {th }}, 2018$

Citation: Vidyadhar TU, Kulkarni U. Esophageal cancer and treatment modalities. Gen Surg Open A Open J. 2018; 1(1): 1-3

\begin{abstract}
Esophageal cancer is eighth most common cancer worldwide with high biological aggressiveness and poor prognosis. Switching of predominant type from squamous cell carcinoma to adenocarcinoma in Western population, ethnic discrepancies and increased occurrences have identified it as major public health problem. Though monotherapy includes - surgery, radiotherapy and chemotherapy, optimal therapy for esophageal cancer is still debated. Treatment requires a multi-modal approach which includes chemotherapy, radiation therapy with or without surgical follow-up for most patients and chemoradiation for those with inoperable disease; endoscopic therapies, including radiofrequency ablation, endoscopic mucosal resection and endoscopic sub mucosal dissection for Barrett's esophagus/ early carcinoma patients and minimally invasive surgical approaches are standards for esophagectomy. Advancement in diagnostic techniques and the multi-modal treatment approach has led to an improvement in the overall survival of esophageal cancer patients.
\end{abstract}

Key words: Esophageal Cancer, Treatment, Surgery, Radiation, Chemotherapy, Chemoradiation.

Abbreviations: EC: Esophageal Carcinoma; ESCC: Esophageal Squamous Cell Carcinoma; EAC: Esophageal Adenocarcinoma; BE: Barrett’s Esophagus; CT: Computed Tomography; RFA: Radiofrequency Ablation; EMR: Endoscopic Mucosal Resection; ESD: Endoscopic Sub Mucosal Dissection; THE: Transthoracic Esophagectomy; MIE: Minimally Invasive Esophagectomy; RAMIE: Robotic-Assisted Minimally Invasive Esophagectomy; 5-FU: 5-Fluorouracil.

\section{INTRODUCTION}

Esophageal carcinoma (EC) is the eighth most common cancer ranking sixth in mortality worldwide, with developing countries accounting for more than $80 \%$ cases as well as deaths. ${ }^{1}$ Its aggressive nature and low survival rate makes it one of the deadliest cancer with a low 5 -year relative survival rate of meagre $17 \%$. This low survival rate is due to its late stage diagnosis, with more than $50 \%$ patients already metastasized and nearly $30 \%$ with locally advanced stages. ${ }^{2}$ EC is a male dominant disease and is $2-3$ times more common in men than women. ${ }^{1}$ Recent advances in image-enhanced endoscopic techniques and therapeutics have paved way for its early detection and improved clinical management. ${ }^{3}$

\section{ESOPHAGEAL CARCINOMA}

The two most common histological types of EC are Esophageal Squamous Cell Carcinoma (ESCC) and Esophageal Adenocarcinoma (EAC). Though ESSC is more common histological type worldwide,
EAC occurrences have increased dramatically in past 40 years making it more predominant of the two. Sarcomas and small cell carcinomas account for $1-2 \%$ of EC, lymphomas, carcinoids, melanomas being even rarer. $^{3}$ ESCC mainly affects middle/lower esophagus, major causes being alcohol and tobacco consumption. EAC affects the distal esophagus with high grade dysplasia and obesity being the risk factors apart from its link with gastro esophageal reflux disease which when untreated progresses to Barrett's esophagus (BE). ${ }^{4,5}$ The incidence increases with age in both subtypes.

EC is highly aggressive and may spread by direct extension, lymph system or hematogenous metastasis; latter being more common in advanced stages. ${ }^{6}$ Accurate pretreatment staging is crucial as it directly affects the treatment options as well as prognosis. TNM system developed by the American Joint Committee on Cancer is used for assessment as it concentrates on the critical aspect of distinguishing the depth of invasion of the primary tumor (Table 1) which in turn helps determine the stage-specific treatment protocols. (Table 2$)^{7}$ 
Table 1. TNM System indicating depth of invasion in T staging.

\begin{tabular}{|l|l|}
\hline Stage of Tumor & Description \\
\hline Tis & Carcinoma in situ \\
\hline T1 & Tumors invade lamina propria or submucosa \\
\hline T2 & Tumors invade muscularis propria \\
\hline T3 & Tumors invade adventitia \\
\hline T4 & Tumors invade adjacent structures \\
\hline N0 & No regional lymph node metastases \\
\hline N1 & Regional lymph node metastases \\
\hline M0 & No distant metastasis \\
\hline M1a, M1b & Distant metastasis \\
\hline
\end{tabular}

Table 2. TNM System indicating depth of invasion in T staging.

\begin{tabular}{|c|c|c|c|l|}
\hline Stage & Tumor & Node & Metastasis & Therapeutic Options \\
\hline 0 & Tis & N0 & M0 & Local ablative therapy \\
\hline I & T1 & N0 & M0 & Surgery \\
\hline IIA & T2 & N0 & M0 & Surgery \\
\hline & T3 & N0 & M0 & - \\
\hline IIB & T1 & N1 & M0 & $\begin{array}{l}\text { Neo-adjuvant therapy with or without } \\
\text { surgery }\end{array}$ \\
\hline & T2 & N1 & M0 & - \\
\hline III & T3 & N1 & M0 & $\begin{array}{l}\text { Neo-adjuvant therapy with or without } \\
\text { surgery }\end{array}$ \\
\hline & T4 & Any N & M0 & - \\
\hline IVA & Any T & Any N & M1a & $\begin{array}{l}\text { Chemotherapy or radiation therapy with or } \\
\text { without surgery }\end{array}$ \\
\hline IVB & Any T & Any N & M1b & Palliative treatment \\
\hline
\end{tabular}

\section{DIAGNOSIS}

EC patients usually present with dysphagia or odynophagia. Confirmation of diagnosis is carried out using imaging tools such as endoscopy, endoscopic ultrasonography, esophagography, computed tomography $(\mathrm{CT})$ and positron emission tomography and is followed by clinical staging. ${ }^{8}$ Laparoscopy and thoracoscopy are minimally invasive techniques used for staging where CT fails, while bronchoscopy is used to check for tracheobronchial involvement. Magnetic resonance imaging is rarely indicated to evaluate liver, spine and other lesions.

\section{TREATMENT}

Treatment plan for EC depends on the location and size of lesion, presence/absence of metastases, histological type and patient goals though optimal induction therapy remains controversial. Endoscopic therapies, including radiofrequency ablation (RFA), endoscopic mucosal resection (EMR) and endoscopic sub mucosal dissection (ESD), are considered standard treatment modality for BE and early carcinoma. ${ }^{9} 10$ Multimodal treatment, which includes induction therapy - radiation, chemotherapy and chemo-radiotherapy often followed by resection surgical/non-surgical as per disease progression, used in adjuvant or neo-adjuvant setting, remains the primary mode of treatment for most patients.

\section{SURGERY}

For loco-regional disease, surgery is considered primary mode of treatment with mortality rate as low as 3\%, 5-year survival rate of $10-40 \%$, and distant metastasis as the most common mode of treatment failure. ${ }^{11} \mathrm{~A}$ total esophagectomy, although controversial, has become a suggested approach owing to anatomy of the esophageal lymphatics which favors longitudinal spread. Primary esophagectomy techniques are transhiatal esophagectomy (THE) and transthoracic esophagectomy, former of which is associated with reduced operating time, length of stay in hospital, postoperative respiratory complications, and decreased early mortality while the latter with fewer anastomosis leaks, anastomotic strictures, and vocal cord paralysis; with no significant difference between 5 -year survival rate. ${ }^{12}$ Minimally invasive esophagectomy (MIE) is preferred standard of care with low mortality rate $(1.4 \%)$ along with robotic-assisted minimally invasive esophagectomy (RAMIE) which has an advantage of improved lymph node dissection..$^{13}$ In absence of metastasis, another treatment option is EMR/ESD which aids staging early carcinoma, offers better chance for cure in localized and locally advanced disease while maintaining a five year survival rate between $15-20 \%$. It can be used in conjunction with RFA and cryotherapy ablation to eradicate BE. ${ }^{10,14}$

\section{RADIATIONTHERAPY}

Radiation therapy when evaluated alone for local control of EC had only 6\% 3-year survival rate. ${ }^{15}$ Though it was the sole treatment modality used for inoperable ESCC, it had negligible effect on EAC, which is radio-insensitive. Traditionally, it is a standard treatment used for EC, either alone or in combination with surgery but is not recommended as a single therapy due to its association with short as well as long term morbidity and tendency to increase perioperative complications as well as mortality without improving survival. ${ }^{16}$ External beam irradiation such as 30 Gy (27) or 49-56 Gy is commonly used and though not capable of converting unresectable cancers into resectable ones, it helps decrease loco-regional recurrence. ${ }^{17}$

\section{CHEMOTHERAPY}

Chemotherapy as a single agent has been shown to have a positive response in up to $50 \%$ cases. It may improve baseline dysphagia, downstage a tumor increasing resection rates and improving local control, treat micro-metastatic disease not detected in imaging and has capacity to specify biologic behavior of the tumor based on patient response thus aiding the course of further therapy. ${ }^{18}$ But, its relapse rates are high with low long-term survival, toxicity induced morbidity/ mortality, disease progression and delay of definitive surgical treatment. ${ }^{19}$ Platinum agents (Cisplatin, Carboplatin and Oxaliplatin) and 5-fluorouracil (5-FU) are the most common agents for primary management while Vindesine, Vinorelbine (Navelbine), Topoisomerase Inhibitors and Taxanes (Docetaxel and Paclitaxel- response rates of 20\% to $34 \%$ ) are newer effective single agent chemotherapeutics. ${ }^{20}$ Recent literature suggests that a multi-modal approach has yielded better results over single chemotherapy. For example, a 3-drug regimen of DCF (Docetaxel and Cisplatin plus 5-FU) has exhibited a 62\% response rate. $^{21}$

\section{CHEMORADIOTHERAPY/CHEMORADIATION}

The aim of concomitant chemotherapy and radiation therapy is to improve local control by radio-sensitizing while simultaneously treating micro-metastases. It has been observed that higher drug concentrations along with exposure yields better results but, is associated with significant toxicity and hence is considered only if the patient is in good health. Accordingly, a combination of 5-FU, Mitomycin and radical radiotherapy is often used for EC management. ${ }^{22}$ Cisplatin and 5-FU are synergistic with radiation $(30 \mathrm{~Gy})^{23}$, and Gemcitabine, with its potent radio-sensitization capability is another candidate. ${ }^{24}$ 


\section{CONCLUSION}

EC is an aggressive disease with ESCC being the globally common histological subtype although EAC cases have superseded ESCC in the Western world, especially in Caucasian males. Management of EC is based on histologic type and stage at which it is diagnosed as there is marked difference between the two subtypes not only in characteristics but also in treatment outcomes. The three primary treatment options of EC were surgery, chemotherapy, and radiation therapy which had poor overall survival and high relapse rates when used alone. Hence, there was no consensus upon optimal therapy. Literature suggests a more effective approach of multidisciplinary treatment involving usage of advanced surgical techniques such as MIE/RAMIE, endoscopic treatment, radiotherapy, chemotherapy and chemoradiation along with palliation to improve outcomes as well as prolong patient survival. But, despite advances in in surgery, endoscopic therapy and newer therapeutic agents, management of EC remains a great challenge due to its aggressiveness and overall poor survival.

\section{ACKNOWLEDGEMENTS}

The authors acknowledge authors/editors/publishers of all the articles, journals and books cited in this manuscript for contributing the much needed literature to review and conclude this article.

\section{CONFLICT OF INTEREST}

None.

\section{FUNDING}

None.

\section{REFERENCES}

1. Ferlay J, Soerjomataram I, Dikshit R, et al. Cancer incidence and mortality worldwide: sources, methods and major patterns in GLOBOCAN 2012. Int J Cancer. 2015; 136: E359-386. doi: 10.1002/ ijc. 29210

2. Zhang Y. Epidemiology of esophageal cancer. World J Gastroenterol. 2013; 19: 5598-5606. doi: 10.3748/wjg.v19.i34.5598

3. Pennathur A, Gibson MK, Jobe BA, Luketich JD. Oesophageal carcinoma. Lancet. 2013; 381: 400-412. doi: 10.1016/S01406736(12)60643-6

4. Spechler SJ. Barrett esophagus and risk of esophageal cancer: A clinical review. JAMA. 2013; 310: 627-636. doi: 10.1001/jama.2013.226450

5. Nieman KM, Romero IL, Van Houten B, Lengyel E. Adipose tissue and adipocytes support tumorigenesis and metastasis. Biochim Biophys Acta. 2013; 1831: 1533-1541. doi: 10.1016/j.bbalip.2013.02.010

6. Postlethwait RW. Carcinoma of the thoracic esophagus. Surg Clin North Am. 1983; 63: 933-940.

7. Greene F, Fritz A, Balch C. AJCC cancer staging handbook part III: digestive system 9-esophagus. $6^{\text {th }}$ ed. New York, NY: Springer-Verlag, 2002.

8. National Comprehensive Cancer Network (NCCN) clinical practice guidelines in oncology: Esophageal and esophagogastric junction cancers. Version 3. Website: http://www.nccn.org/professionals/ physician_gls/pdf/esophageal.pdf. Accessed 2015.

9. Shaheen NJ, Sharma P, Overholt BF, et al. Radiofrequency ablation in barrett esophagus with dysplasia. N Engl J Med. 2009; 360: 2277-2288.

\section{doi: 10.1056/NEJMoa0808145}

10. Pech O, May A, Manne H, et al. Long-term Efficacy and Safety of Endoscopic Resection for Patients With Mucosal Adenocarcinoma of the Esophagus. Gastroenterology. 2014; 146: 652-660. doi: 10.1053/j. gastro.2013.11.006

11. Martin IG, Young S, Sue-Ling H, Johnston D. Delays in the diagnosis of oesophagogastric cancer: A consecutive series. BMJ. 1997; 314: 467-470.

12. Boshier PR, Anderson O, Hanna GB. Transthoracic versus transhiatal esophagectomy for the treatment of esophagogastric cancer: A meta-analysis. Ann Surg. 2011; 254: 894-906. doi: 10.1097/ SLA.0b013e3182263781

13. Luketich JD, Pennathur A, Awais O, et al. Outcomes after minimally invasive esophagectomy: review of over 1000 patients. Ann Surg 2012; 256: 95-103. doi: 10.1097/SLA.0b013e3182590603

14. Nelsen EM, Hawes RH, Iyer PG. Diagnosis and management of Barrett's esophagus. Surg Clin North Am. 2012; 92: 1135-1154. doi: 10.1016/j.suc.2012.07.009

15. Earlam R, Cunha-Melo JR. Oesophageal squamous cell carcinoma: I. A critical review of surgery. Br J Surg. 1980; 67: 381-390.

16. Wong R, Malthaner R. Combined chemotherapy and radiotherapy (without surgery) compared with radiotherapy alone in localized carcinoma of the esophagus. Cochrane Database Syst Rev. 2003; (1): CD002092.

17. Hambraeus GM, Mercke CE, Wille'n R, et al. Prognostic factors influencing survival in combined radiotherapy and surgery of squamous cell carcinoma of the esophagus with special reference to a histopathologic grading system. Cancer. 1988; 62: 895-904. doi: 10.1002/1097-0142(19880901)62:5<895::AIDCNCR2820620508>3.0.CO;2-0

18. Kato H, Nakajima M. Treatments for esophageal cancer: A review. Gen Thorac Cardiovasc Surg. 2013; 61: 330-335. doi: 10.1007/s11748013-0246-0

19. Enzinger PC, Ilson DH, Kelson DP. Chemotherapy in esophageal cancer. Semin Oncol. 1999; 25(5 suppl 15): S12-20.

20. Ajani JA, Ilson DH, Daugherty K, et al. Activity of taxol in patients with squamous cell carcinoma and adenocarcinoma of the esophagus. $J$ Natl Cancer Inst. 1994; 86: 1086-1091.

21. Hironaka S, Tsubosa Y, Mizusawa J, et al. Phase I/II trial of 2-weekly docetaxel combined with cisplatin plus fluorouracil in metastatic esophageal cancer. (JCOG0807). Cancer Sci. 2014; 105: 1189-1295. doi: $10.1111 /$ cas. 12486

22. Keane TJ, Harwood AR, Elkahim T, et al. Radical radiation therapy with 5-FU uorouracil infusion and mitomycin $\mathrm{C}$ for oesophageal squamous carcinoma. Radiother Oncol. 1985; 4: 205-210.

23. Liu J, Yue J, Xing L, Yu J. Present status and progress of neoadjuvant chemoradiotherapy for esophageal cancer. Front Med. 2013; 7: 172-179. doi: $10.1007 / \mathrm{s} 11684-013-0268-0$

24. Spiridonidis $\mathrm{CH}$, Laufman LR, Jones J, et al. Phase I study of docetaxel dose escalation in combination with . xed weekly gemcitabine in patients with advanced malignancies. J Clin Oncol. 1998; 16: 3866 3873. doi: 10.1200/JCO.1998.16.12.3866 